\title{
SUPPORT MODEL OF MATERIAL REQUIREMENTS PLANNING IN A COAL MINE
}

\author{
Katarzyna Jakowska-Suwalska ${ }^{1)}$, Maciej Wolny ${ }^{2)}$ \\ ${ }^{1)}$ Faculty of Organisation and Management, Silesian University of Technology, \\ Roosevelta 26-28, 41-800 Zabrze, Poland, \\ E-mail: katarzyna.jakowska-suwalska@polsl.pl,maciej.wolny@polsl.pl
}

\begin{abstract}
This paper presents a multiple criteria decision making model of material requirements planning in a coal mine. The model is built on the basis of historical data of material consumption and two criteria are considered in the model: (a) probability of a lack of material and (b) deviations of the order size from the material consumption volumes in the last $\mathrm{n}$ periods. The work assumes that the volume of material consumed is a continuous random variable with a known distribution. In the model proposed it is also assumed that the costs of material order volume are limited. The problem analyzed with the two criteria is solved by using goal programming and as a result, two non-dominated solutions are received. The game theory approach to multiple attribute decision problems is used to choose the final solution. Copyright $@$ Research Institute for Intelligent Computer Systems, 2015. All rights reserved.
\end{abstract}

Keywords: multiple attribute decision support, inventory control, material requirement planning, non-cooperative game.

\section{INTRODUCTION}

The main objective of the work is to present and to analyze the problem of multiple criteria decision making support on the basis of the example connected with material requirement planning in a hard coal mining enterprise. The production process in such company depends on many nondeterministic factors (geological conditions, among others), therefore many decisions are taken in the conditions of risk or uncertainty.

In the work the method of supporting the material requirement planning is presented which consists of two stages: modelling and problem solving. In the first stage a multi-objective optimization model is formed with two groups of criteria. The first group includes the criteria regarding the probability of material deficiency for the works planned, the second one - the deviation of order amount from the real (historical) consumption values of the examined materials. In the second stage the problem is solved by method of lexicographic goal programming [2 p. 17]. Each group of criteria, after introducing the goal variables, was aggregated into one criterion by applying a scalarization function with the weights assigned by a decision-maker basing on the material importance in the mining process.

In the case when the decision-maker sets the priorities of the particular goals, there is exactly one solution to the problem received (or more but of the same value of the objective function). In case when the decision-maker does not want or cannot rank the criteria from the most to least important, a multiple solution to the problem is proposed for all possible hierarchies of objective function. Then there is a finite set of effective solutions obtained, so in result, a discrete problem. In order to choose the solution interactive methods may be used or, as it is proposed in the work, the method based on the game theory.

The multiple attribute problem modelling in the field of game theory was analyzed relatively rarely. The works were mostly based on model construction in a form of zero sum game [16]. In such model, the decision-maker serves the function of arbiter in the game, the strategies of one player are the analyzed decision variants (the assumption is made about a finite decision variants set). However, the strategies of the second player are the criteria (with the assumption about maximizing all the objective functions). The concept of the solution to the problem stated is to ground on using the mini and maxi criteria as well as to choose an alternative which guarantees the greatest one from the possible minimal levels achieved in the goal set (the measurement of which are the considered criteria). At the same time, it should be taken into account that multiple attribute problem modelling in the form of zero sum game highlights a conflict occurring in 
the problem - zero sum games serve for antagonistic situations modelling in which there is an extreme conflict (in two-player game the payoff of one player is at the same time the loss of the other one). However, it has been noticed that in the multiple attribute problems such a strong conflict does not always occur [7 p. 534], but only when analyzing efficient solutions, the value of improvement of one objective function at the expense of another one causes conflict [7 p. 533-543].

The inspiration for the considerations raised in the hereby work is a concept by Maddani and Lund [17] connected with the analysis of multiple attribute decision problem in the form of multi-player noncooperative game.

The starting point for model construction in the form of a game is the identification of relationships between the multiple attribute problem and the game. These relationships are presented in Fig. 1.

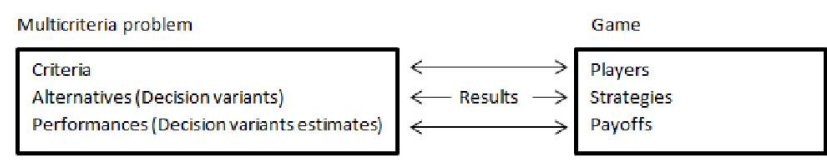

Fig. 1 - Relationships between multi attribute decision problems and models in the game theory.

Source: Madani, Lund (2011).

When building a multiple attribute model in the form on a non-cooperative multi-player game, each player is linked to one criterion, strategies of each player are determined by the examined alternatives and the payoffs of the players by the estimates of decision variants [28]. Such problem transformation implies the necessity of determining the payoffs of the players in the situation when players-criteria choose different strategies-variants. The choice of the acceptable decision, in such game, is correspondent to a situation when all players-criteria use the same strategy, that is they choose the same decision variant. The independence of strategy selection by the player means that there are possible situations in which at least one of the players-criteria chooses another variant. In the work by Madani and Lund [17] the issue considered with four decision variants and one of the variants means the current state (status quo), and also two criteria are analyzed connected with two groups of stakeholders. In the situation when players-criteria choose different strategies-variants, then the current state is maintained - payoffs of the players in this situation are the same as in case of a simultaneous choice of status quo alternative. From the point of view of players-criteria in this game, these situations are undistinguishable. The model in the form of a game is analyzed and solved with the use of noncooperative stability definition [5]. The game presented by Madani and Lund requires the existence of status quo decision variant (strategy), however, one should notice that it is a specific case of decision problem.

Taking into account the considerations above, the multiple attribute decision problem may be understood as a some kind of abstraction - a game played among the criteria in the decision-maker's mind. Such an approach to the issue allows the possibility of multi-stage game and considering the stability of obtained solution understood as stability definition: in the Nash's meaning [20], general meta-rationality (GMR, [11]), symmetric metarationality (SMR, [11]), sequential stability (SEQ [8]), limited move stability (LMS [31], [15], [5]) and non-myopic stability (NMS [3]).

The analysis of one-time played situation (with perfect information) is also possible as well as the use of the concept of risk dominance [10] for coordinating the actions of players.

\section{GENERAL FORM OF THE MODEL}

Let's assume the consumption, per ton of the mining product, of $M_{i}$ material $(i=1,2, \ldots, s)$ to be a random variable $X_{i}$ with a known distribution $F_{i}$ and $z_{i}$ be the size of the order of $M_{i}$ material per one ton of mining product. Assuming that there should be $z_{i}$ order size for $M_{i}$ material, which with the highest probability covers the requirement for this material. It is known that material storage increases the company's costs. Therefore, such an order size for the material should be found and its lowest possible amount purchased under the condition that it does not deviate considerably from the past level of material requirement and the purchase costs of all the materials do not exceed a certain pre-determined $K$ value. It was assumed in this work that the consumption of $M_{i}$ material per ton of the mining product: $x_{i l}, x_{i 2}, \ldots, x_{i n}$ in the $n$ previous periods $(i=1,2, \ldots, s)$ does not show any trend or periodical fluctuations. It is also supposed that the $x_{i 1}, x_{i 2}, \ldots, x_{i n}$ values are the only information about the mining conditions affecting the level of material consumption in the past.

When: $m_{\mathrm{i}}-$ expected value of the random variable $X_{i}, S_{i x}$ - standard deviation of the random variable $X_{i}$.

The objective functions, for each $M_{i}$ material are: (a) - probability of a lack of $M_{i}$ material $\left(F_{i}\left(z_{i}\right) \rightarrow \max i=1,2, \ldots, p\right),(b)-$ deviations of the $z_{i}$ order size from the material consumption volumes: $x_{i 1}, x_{i 2}, \ldots, x_{i n}$ in the last $n$ periods $\left(\left|x_{i t}-z_{i}\right| \rightarrow \min , i=\right.$ $1,2, . ., p, t=1,2, \ldots, n)$.

In order to compare the results according to the separate groups of criteria (a), (b) the following 
standardization was performed: $z_{i}^{s}=\frac{z_{i}-m_{i}}{S_{i x}}$, $x_{i t}^{s}=\frac{x_{i t}-m_{i}}{S_{i x}},\left|x^{s}{ }_{i t}-z_{i}^{s}\right|=\frac{\left|x_{i t}-z_{i}\right|}{S_{i x}}$.

The model may therefore be written in the following form:

$$
\left\{\begin{array}{l}
F_{i}\left(z_{I}^{s}\right) \rightarrow \max \\
\left|x_{i t}^{s}-z_{i}^{s}\right| \rightarrow \min \\
\sum_{i=1}^{s} c_{i} z_{i} W \leq K \\
z_{i} \geq 0 \\
z_{i}=z_{i}^{s} S_{i x}+m_{i} \\
i=1,2, \ldots, p \\
t=1,2, \ldots, n
\end{array}\right.
$$

where: $c_{i}$ - price of one unit of the $M_{i}$ material, $W-$ mining production planned, $K$-funds available for $M_{1}, M_{2}, \ldots, M_{p}$ materials purchase.

Let the variables $v_{i}^{F+}, v_{i t}^{Q^{-}} \geq 0$ be the goal variables, so that:

$$
\begin{aligned}
& F\left(z_{i}^{s}\right)+v_{i}^{F+}=1, \\
& \left|x^{s}{ }_{i t}-z_{i}^{s}\right|-v_{i t}^{Q-}=0, \\
& i=1,2, \ldots, p, \\
& t=1,2, \ldots, n .
\end{aligned}
$$

The problem (1) may be then written in the following form:

$$
\left\{\begin{array}{l}
v_{i}^{F+} \rightarrow \min , \\
v_{i t}^{Q-} \rightarrow \min , \\
F\left(z_{i}^{s}\right)+v_{i}^{F+}=1 \\
\left|x_{i t}^{s}-z_{i}^{s}\right|-v_{i t}^{Q-}=0, \\
\sum_{i=1}^{p} c_{i} z_{i} W \leq K, \\
v_{i}^{F+}, v_{i t}^{Q-} \geq 0 \\
z_{i}=z_{i}^{s} S_{i x}+m_{i}, \\
i=1,2, \ldots, p, \\
t=1,2, \ldots, n .
\end{array}\right.
$$

Multi-objective optimization problems are usually solved by scalarization ([21], [2]). If we denote the weight given by the decision-maker to $\mathrm{Mi}$ material as ui on the basis of its importance in the production process, so that $u_{1}, u_{2}, \ldots, u_{s}>0$ and $u_{1}+u_{2}+\ldots+u_{s}=1$, next scalarization may be performed in the following way:

$$
\begin{aligned}
& s\left(u,\left(v_{1}^{F+}, v_{2}^{F+}, \ldots, v_{p}^{F+}\right)\right)=\sum_{i=1}^{p} u_{i} v_{i}^{F+}, \\
& s\left(u,\left(v_{1 t}^{Q-}, v_{2 t}^{Q-}, \ldots v_{p t}^{Q-}\right)\right)=\sum_{i=1}^{p} u_{i} v_{i t}^{Q-} .
\end{aligned}
$$

Thus, the model obtained in this way will be of the following form:

$$
\left\{\begin{array}{l}
\sum_{i=1}^{p} u_{i} v_{i}^{F+} \rightarrow \min , \quad(a) \\
\sum_{i=1}^{p} u_{i} v_{i t}^{Q^{-}} \rightarrow \min , \quad(b) \\
F\left(z_{i}^{s}\right)+v_{i}^{F+}=1, \\
\left|x_{i t}^{s}-z_{i}^{s}\right|-v_{i t}^{Q-}=0,
\end{array},\right.
$$

As the goal variables $v_{i t}^{Q-} t=1,2, \ldots, n$, appear in the set of criteria (b), a process for discounting these observations may be run using weights. Let $w_{t}$ be the weight for $t$ period. For example, using harmonic weights:

$$
w_{t}=w_{t-1}+\frac{1}{n(n+1-t)} \text { for } t=1,2, \ldots, n \text { with } w_{0}=0 .
$$

In this case, the set of criteria (b) may be described using only one objective function:

$$
\sum_{t=1}^{n} \sum_{i=1}^{p} u_{i} w_{t} v_{i t}^{Q-} .
$$

Thus, the model takes the following form:

$$
\left\{\begin{array}{l}
\sum_{i=1}^{p} u_{i} v_{i}^{F+} \rightarrow \min , \\
\sum_{t=1}^{n} \sum_{i=1}^{p} u_{i} w_{t} v_{i t}^{Q-} \rightarrow \min , \\
F\left(z_{i}^{s}\right)+v_{i}^{F+}=1, \\
\left|x_{i t}^{s}-z_{i}^{s}\right|-v_{i t}^{Q-}=0, \\
z_{i}=z_{i}^{s} S_{i x}+m_{i} \\
\sum_{i=1}^{s} c_{i} z_{i} W \leq K \\
v_{i}^{F+}, v_{i t}^{Q-} \geq 0 \\
i=1,2, \ldots, p \\
t=1,2, \ldots, n .
\end{array}\right.
$$


In case when all the materials are equally important in the manufacturing process, the model (4) may take the following form:

$$
\left\{\begin{array}{l}
v \rightarrow \min , \\
\sum_{t=1}^{n} \sum_{i=1}^{p} w_{t} v_{i t}^{Q-} \rightarrow \min \\
\prod_{i=1}^{p} F\left(z_{i}^{s}\right)+v=1 \\
\left|x^{s}{ }_{i t}-z_{i}^{s}\right|-v_{i t}^{Q-}=0 \\
\sum_{i=1}^{s} c_{i} z_{i} W \leq K \\
v_{i}^{F+}, v_{i t}^{Q-} \geq 0 \\
z_{i}=z_{i}^{s} S_{i x}+m_{i} \\
i=1,2, \ldots, p \\
t=1,2, \ldots, n
\end{array}\right.
$$

This is a model with linear objective functions $(a),(b)$ and a set of non-linear constraints.

In particular, this problem can be solved by lexicographic goal programming. If priorities $\mathrm{P} 1, \mathrm{P} 2$ are set by the decision-maker for the particular objective functions $(a),(b)$, and when the decisionmaker is unable to assign priorities to the particular criteria, the best way is to determine an optimal solution for all of the possible combinations of priorities. In this way a finite set of solutions is created, which then may be presented to the decision-maker and he can choose the most satisfying ones from the elements of the set. Another way is to use a method which would allow distinguishing the best solution from the set. To this end the methods from the game theory may be used.

\section{GAME THEORY APPLICATION TO CHOOSE THE SOLUTION TO A MULTI ATTRIBUTE PROBLEM}

If there is a multiple attribute decision problem in the following form:

$$
\max _{y \in Y} \Psi(y)=\max _{y \in Y}\left[f_{1}(y), f_{2}(y), \ldots, f_{k}(y)\right],
$$

where $Y$ is a finite set of acceptable (feasible) decision variants $y=\left\{y_{1}, y_{2}, \ldots, y_{r}\right\}, f_{j}$ is a $j$-number criterion-function defined on the set: $Y(j=1,2, \ldots, k)$, $\Psi(y)$ is the vector grouping all the targeted functions, $f_{j}(y)$ designates the assessment of the decision variants in relation to the $j$-number criterion. Furthermore, all of the estimates of alternatives in relation to all criteria are given. The solution to the problem of vector optimization (5) is a set of effective solutions (Pareto-optimal).
Using the relationships presented in figure 1, the problem (5) may be transformed to a noncooperative non-zero sum game with $k$ players in the standard form:

$$
G=(\Phi, H)
$$

where $\Phi=Y^{k}$ is a set of all possible situations in the game, and $H$ is the function of payoffs for the players, determined on the $\Phi$ set. Each situation in the game is clearly determined by the vector of pure strategies used by each player. Therefore, the vector $\phi=\left(y_{i 1}^{1}, y_{i 2}^{2}, \ldots, y_{i k}^{k}\right), y_{i j}^{j} \in Y$, the components of which are the strategies of particular players chosen in the given situations, is the element of the $\Phi$ set. The $i$ number strategy is chosen by the $j$-number player $(i$, $j=1,2, \ldots, n)$. The situation, in which all players choose the strategy related to the same $i$-number decision-making variant, is described by:

$$
\phi_{i}=\left(y_{i}^{1}, y_{i}^{2}, \ldots, y_{i}^{n}\right), y_{i}^{1}=y_{i}^{2}=\ldots=y_{i}^{n} .
$$

Let $y^{*}$ designate the strategy related to an alternative with status quo character, and then the payoff function is determined in the following way:

$$
H(\phi)=\left\{\begin{array}{l}
\left(f_{1}\left(y_{i}\right), f_{2}\left(y_{i}\right), \ldots, f_{k}\left(y_{i}\right)\right) \\
\text { for } \phi_{\mathrm{i}}, \\
\left(f_{1}\left(y^{*}\right), f_{2}\left(y^{*}\right), \ldots, f_{k}\left(y^{*}\right)\right) \\
\text { for other situations. }
\end{array}\right.
$$

The results of research presented in Madani's and Lund's thesis indicate that the analysis and features of a game defined in such way depend on the status $q u o$ variant which first of all has to exist, i.e. it has to belong to the set $Y$.

The game presented is played in the mind of the decision-maker so the analysis of the problem may be conducted with the use of the definition of stability presented in Table 1 . The various definitions of stability differ from one another mainly in terms of the horizon of anticipating moves, the possibility of making the situation worse in a given move and the required information about players' preferences. Especially, it has to be noted that the definitions of stability presented in the table relate to a particular player and the analyzed situation in the game is stable if it is stable for each players.

\footnotetext{
${ }^{1}$ With the assumption that the status quo variant exists (in such meaning that the lack of choice of the same variant by all players-criteria corresponds to a lack of change in the existing state).
} 
Table 1. Definitions of stability.

\begin{tabular}{|c|c|c|c|c|}
\hline \multirow[b]{2}{*}{ 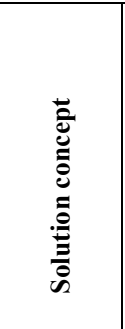 } & \multirow[b]{2}{*}{ Description of stability } & \multicolumn{3}{|c|}{$\begin{array}{c}\text { Characteristics of } \\
\text { stability }\end{array}$} \\
\hline & & 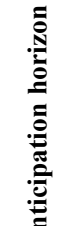 & 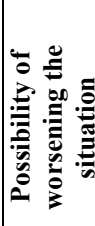 & 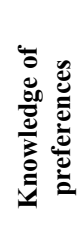 \\
\hline 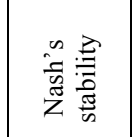 & $\begin{array}{l}\text { The player has no possibility of } \\
\text { one-sided improvement of his } \\
\text { situation (transfer to more } \\
\text { preferred state) }\end{array}$ & 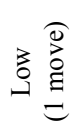 & $\stackrel{\circ}{z}$ & है \\
\hline 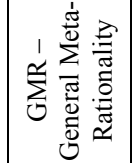 & $\begin{array}{c}\text { All (one-sided) improvements } \\
\text { of a given player are blocked } \\
\text { by other one-sided moves of } \\
\text { other players }\end{array}$ & 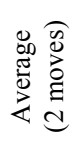 & 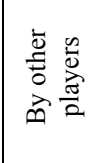 & $\begin{array}{l}\infty \\
\stackrel{n}{\overrightarrow{0}} \\
\stackrel{\vec{\omega}}{2}\end{array}$ \\
\hline 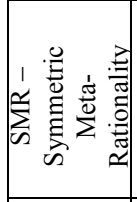 & $\begin{array}{l}\text { All (one-sided) improvements } \\
\text { of a given player are blocked } \\
\text { by other one-sided moves of } \\
\text { other players even after a } \\
\text { possible response of a given } \\
\text { (analyzed) player }\end{array}$ & 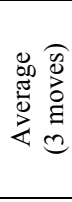 & 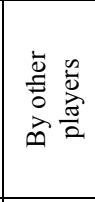 & 㐫 \\
\hline 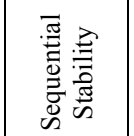 & $\begin{array}{c}\text { All (one-sided) improvements } \\
\text { of a given player are blocked } \\
\text { by other one-sided moves of } \\
\text { other players }\end{array}$ & 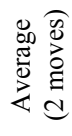 & z & 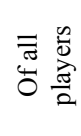 \\
\hline 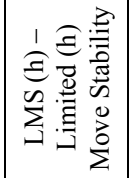 & $\begin{array}{l}\text { It is assumed that all players } \\
\text { are acting optimally, the } \\
\text { number of transfers between } \\
\text { situations in the game is strictly } \\
\text { limited }\end{array}$ & 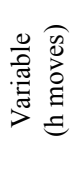 & 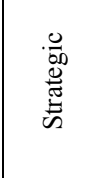 & 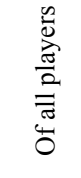 \\
\hline 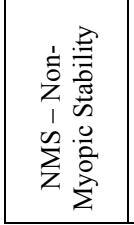 & $\begin{array}{l}\text { A case of stability in a } \\
\text { restricted number of moves, in } \\
\text { which the number of transfers } \\
\text { between the conditions tends to } \\
\text { infinity (however, there is no } \\
\text { way to obtain the condition in } \\
\text { which the analysis was started) }\end{array}$ & 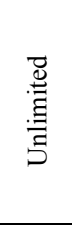 & 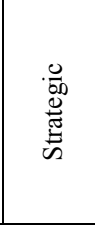 & 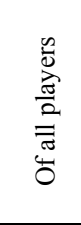 \\
\hline
\end{tabular}

Source: Madani K., Hipel K.W. (2011). Non-Cooperative Stability Definitions for Strategic Analysis of Generic Water Resources Conflicts. Water Resources Management 25, 2011 p. 1949-197

In a particular way, the description of stability in the meaning of LMS and the numerical listing of the idea of risk dominance, will be presented in the analysis of the problem related to the enhancement of material requirement planning in hard-coal mining plants.

While considering the multiple attribute problem understood as a game that is played once, one can use the concept of risk dominance [10]. The essence of such approach is based on choosing a dominant strategy related to risk, while the measure of risk in this case is the probability (subjective) of using relevant strategies by the players, with perfect information about the payoffs and under the assumption that the players behave rationally in order to coordinate their actions.

\section{EXAMPLE OF THE USE OF THE MULTI-OBJECTIVE MODEL TO DETERMINE THE ORDER SIZE FOR WOOD AND POLYURETHANE ADHESIVE}

Wood and polyurethane adhesive is consumed in hard-coal mines [22].

The hypothesis that wood consumption is a random variable with normal distribution $N(0,00358 ; 0.0086)$ is not rejected at the significance level of 0,05 (Kolmogorov-Smirnov test). The hypothesis that polyurethane adhesive consumption is a random variable with the normal distribution $N(0,122 ; 0,045472)$ is not rejected at the significance level of 0,05 (Kolmogorov-Smirnov test). The hypothesis that there is no linear correlation between the sizes of wood consumption and polyurethane adhesive consumption is not rejected at the significance level of 0,05 .

Table 2 presents the average unit prices of wood and adhesive, together with annual mining production planned and the annual level of expenditure on wood and polyurethane adhesive planned.

Table 2. Unit costs of wood and adhesive, annual mining production planned and annual level of expenditure on wood and polyurethane adhesive planned.

\begin{tabular}{|c|c|}
\hline price per kg of adhesive $-c_{1}$ & 13,75 PLN \\
\hline price per m3 of wood $-c_{2}$ & 296 PLN \\
\hline mining production planned $-W$ & $4000000 \mathrm{t}$ \\
\hline $\begin{array}{c}\text { maximum expenditure on } \\
\text { materials }-K\end{array}$ & 950000,00 PLN \\
\hline
\end{tabular}

In model (4) the harmonic weights: $w_{i}(i=1$, $2, \ldots, 36)$ were used and it was assumed that both materials are equally important in the mining process, so the weights satisfy: $u_{1}=u_{2}=0,5$. Moreover, it was assumed that the decision-maker has not set the priorities of particular criteria. Table 3 presents the solutions to the problem (4') with various sets of priorities.

The estimates of the status quo variant were based on the method of determining the material requirements that is currently in use.

Grounding on the relationships presented in Fig. 1, the problem was presented as a game in a normal form of (5):

$$
\left[\begin{array}{ccc}
(0.14876 ;-0.20332) & (0.03745,-0.20981) & (0.03745,-0.20981) \\
(0.03745,-0.20981) & (0.04474 ;-0.16251) & (0.03745,-0.20981) \\
(0.03745,-0.20981) & (0.03745,-0.20981) & (0.03745,-0.20981)
\end{array}\right]
$$

The matrix (9) is the realization of the concept of payoff function (8), in which the payoffs of the 
second player are presented by negative values due to the direction of the optimization of the given criterion-function.

Table 3. Values of solutions with various sets of priorities given to the objective functions of the problem (4').

\begin{tabular}{|c|c|c|}
\hline$z_{1}$-adhesive in $\mathrm{kg} / \mathrm{t}$ & 0,0875946 & 0,0454681 \\
\hline$z_{2}$ - wood in $\mathrm{m}^{3} / \mathrm{t}$ & 0,0039546 & 0,0054455 \\
\hline$F\left(\mathrm{z}_{1}\right)$ & 0,22218 & 0,04539 \\
\hline$F\left(z_{2}\right)$ & 0,66955 & 0,98561 \\
\hline Value of the function (A) & 0,14876 & 0,04474 \\
\hline Value of the function (B) & 0,20332 & 0,16251 \\
\hline $\begin{array}{c}\text { Size of the order- adhesive } \\
(\mathrm{kg})\end{array}$ & 35037,8 & 18187,2 \\
\hline Size of the order - wood (m $\left.{ }^{3}\right)$ & 1581,9 & 2178,2 \\
\hline Total cost of the order in PLN & 950000 & 894818 \\
\hline
\end{tabular}

Table 4. Entry data for the problem analysis.

\begin{tabular}{|c|c|c|}
\hline $\begin{array}{c}y \\
\text { decision } \\
\text { variant }\end{array}$ & $\begin{array}{c}\text { Value of the } \\
\text { function (A) } \\
(\max )\end{array}$ & $\begin{array}{c}\text { Value of the } \\
\text { function (B) } \\
(\min )\end{array}$ \\
\hline$y_{1}$ & 0,14876 & 0,20332 \\
\hline$y_{2}$ & 0,04474 & 0,16251 \\
\hline$y^{*}$ & 0,03745 & 0,20981 \\
\hline
\end{tabular}

The analysis of stability of the solutions (situations in the game that correspond to the main diagonal of the matrix) in the understanding by Nash indicates that the situations are stable, none of the players has the variant of one-sided improvement of the situation due to changing the strategy.

The results of the analysis in regards to the other concepts of stability presented in Table 1 are presented in Table 5. The stability of LMS (in a limited number of moves) is especially worth noticing because of the essence of the problem and its features.

Under the assumption that the game is played among the criteria, in the mind of the decisionmaker, it is hard to justify the GMR or SMR stability analysis as they assume the possibilities of transferring to a situation worse for the opponent, only to punish the player (from the point of view of whom the stability of the solution is analyzed) - in other words, a number of antagonistic actions is accepted, which would lead to the analysis of solutions that are irrational from the point of view of all players. The concepts of LMS and NMS, on the other hand, allow the possibility of strategic worsening of the situation if in the perspective of further moves of the players acting rationally and optimally, a situation more preferred than the previous one may be achieved - players make a move only in situations that are better for them (more preferred) $^{2}$, The stability of NMS is a specific version of LMS, in which the horizon of anticipating moves is unrestricted ${ }^{3}$, In the example analyzed in two moves the situations corresponding to the decision variants are analyzed, therefore the stability of LMS is presented in the perspective of two moves, On the other hand, in case of considering $h$ criteria, the $\operatorname{LMS}(h)$ stability should be considered. The stability in the meaning of NMN, due to a specific construction of the game is identical to the stability of $\operatorname{LMS}(h)$,

Table 5. The summary of the stability analysis of the game under consideration.

\begin{tabular}{|c|c|c|c|c|}
\hline \multicolumn{2}{|c|}{ Solution } & $y_{1}$ & $y_{2}$ & $y^{*}$ \\
\hline \multirow{4}{*}{$\begin{array}{c}\text { Stability } \\
\text { occurrence }\end{array}$} & Nash & Yes & Yes & Yes \\
\cline { 2 - 5 } & GMR & Yes & Yes & Yes \\
\cline { 2 - 5 } & SMR & Yes & Yes & Yes \\
\cline { 2 - 5 } & SEQ & Yes & Yes & Yes \\
\cline { 2 - 5 } & LMS & No & No & No \\
\cline { 2 - 5 } & NMS & No & No & No \\
\hline
\end{tabular}

The analysis of the information in table 5 does not clearly indicate the solution to the problem. It is then reasonable to use the approach that considers the problem in the categories of one-stage game both players-criteria select the strategy-alternative at the same time. In the game analyzed there are three equilibriums in the Nash's meaning that are pairwise compared and by the use of the concept of selecting the equilibrium and dominance in regards to the payoffs and risk dominance presented in the Harsanyi's and Selten's thesis [10], one equilibrium will be chosen which corresponds to the choice of a decision variant. Because the equilibrium corresponding to the status quo variant is dominated due to the payoffs by other equilibriums, it will not be analyzed further - the status quo alternative is dominated.

The $\left(\left(y_{1}, y_{1}\right),\left(y_{2}, y_{2}\right)\right)$ is pairwise compared, the example of which will be used to present the concept of risk dominance. It may be seen that there is no payoff dominance (the first equilibrium is preferred by the first player, the second by the second player), As the game is played only once, the players may be guided by the anticipation of their opponents' moves. Let the first player estimate the probability of using the first strategy by the second player as $p$, then the expected value of the first player using the

\footnotetext{
${ }^{2}$ In case of more players-criteria it seems reasonable to allow a strategic worsening of the situation by other players.

${ }^{3}$ The analysis ends with the transfer to the entry condition, i.e. the return to the situation that is analyzed.
} 
first strategy equals

to:

$0,14876 p+0.03475(1-p)=0,11131 p+0,03745$,

and using the second strategy: $0,03745 p+0,04474(1-p)=-0,00729 p+0,04474$,

If the following condition is met: $0,11131 p+0,03745>-0,00729 p+0,04474$, the first player will select the first strategy.

In other words if the first player estimates that $p>0,06147\left(p>p_{0}\right)$ then he will choose the first strategy as he will achieve a greater payoff. The situation may be analysed in a similar way from the point of view of the second player. Let the second player estimate the probability of the first player using the second strategy as $g$. In such case the expected value of using the second strategy by the second player equals: $-0,20981(1-q)-0,16251 q=0,04730 q-0,20981$

and in the first strategy: $-0,20332 \cdot(1-q)-0,20981 q=-0,00649 q-0,20332$

The second player will therefore select the more preferred strategy (equilibrium) if the player estimates that $q>0,2065\left(q>q_{0}\right)$. It may be seen that the first player is more motivated to choose the first strategy than the second player to choose the second strategy $\left(p_{0}<q_{0}\right)$. Accepting the assumption that both players reason in a similar way, the equilibrium should be achieved corresponding to the first alternative - equilibrium $\left(y_{1}, y_{1}\right)$ dominates because of the risk for the equilibrium $\left(y_{2}, y_{2}\right)$,

In the example under consideration, the risk dominance concept used clearly indicates the choice of the $y_{1}$ variant,

\section{SUMMARY AND CONCLUSIONS}

The concept of decision support model concerning the material requirements planning in a mining enterprise is based on the specificity of hardcoal excavation - in a significant way it includes the randomness occurring in the material requirements necessary for production, In this case there should be the examined criteria taken into account:

- probability of material requirements covering,

- deviation from the historical usage.

The procedure suggested bases on a two-phase model. In the first phase there is an issue solved with the use of targeted programming concept, the second phase appears in a situation of a lack of determined priorities regarding criteria function - then from the pre-selected set, determined in the first phase, there may be one solution chosen grounding on the multiple attribute decision making model in the form of non-cooperative game.

The use of multiple attribute problem basing on the game theory does not require a further scalarization of the issue - the variant estimates do not have to be aggregated. In case of game analysis using the stability definition there is only the relationship of direction of preferences significant among the analyzed situations in the game. In the analysis connected with situation selection (equilibrium), which is risk dominant, the probabilities indicated always concern the payoffs of one player, and only when comparing the indicated probabilities it is possible to search for a form of leading to the comparisons of decision variants estimates. In both approaches based on game analysis, the key significance belongs to the reference point of the analysis, that is status quo solution. If such solution is effective in the view of criteria adopted it should be recommended as a solution to the problem.

\section{REFERENCES}

[1] S. J. Brams, D. Wittman, Nonmyopic equilibria in $2 \times 2$ games, Conflict Management and Peace Science, (6) 1 (1981), pp, 39-62.

[2] J. Branke, K. Deb, K. Miettinen, R. Słowiński (Eds), Multiobjective Optimalization Interactive and Evolutionary Approaches, Springer-Verlag, Berlin Heidelberg (2008).

[3] J. P. Brans, L'ingéničrie de la décision; Elaboration d'instruments d'aide 'r la décision, La méthode PROMETHEE in: R. Nadeau and M. Landry, (Eds,), L'aide ŕ la décision: Nature, Instruments et Perspectives d'Avenir, Presses de l’Université Laval (1982), pp. 183-213.

[4] N. B. Chang, C. Wen, and Y. Chen, A fuzzy multi-objective programming approach for optimal management of the reservoir watershed, European Journal of Operational Research, (99) (1997), pp, 289-302.

[5] L. Fang, D. M. Hipel, D. M. Kilgour, Interactive Decision Making: The Graph Model for Conflict Resolution, Wiley, New Yorkb 1993.

[6] J. Figueira, S. Greco, M. Ehrgott (Eds,), Multiple Criteria Decision Analysis, State of the Art Surveys, Springer Science, 2005.

[7] W. Findeisen, (Ed.), Analiza Systemowa Podstawy $i$ Metodologia, PWN, Warszawa 1985. (in Polish).

[8] N. M. Fraser, K. W. Hipel, Conflicts Analysis: Models and Resolutions, North-Holland, New York, 1984.

[9] A. Giarlotta, Passive and active compensability multicriteria analysis (PACMAN), Journal of Multi-Criteria Decision Analysis, (7) 4 (1998), pp. 204-216.

[10] J. C. Harsanyi, R. Selten, A General Theory of Equilibrium Selection in Games, MIT Press, Cambridge-London, 1992. 
[11] N. Howard, Paradoxes of Rationality: Games, Metagames, and Political Behavior, MIT Press, Cambridge, 1971.

[12] E. Jacquet-Lagrčze, Y. Siskos, Assessing a set of additive utility functions for multicriteria decision making: The UTA method, European Journal of Operational Research, (10) 2 (1982), pp, 151-164.

[13] K. Jakowska-Suwalska, A. Sojda, M. Wolny, Wspomaganie planowania wielkości zamówień w kopalni węgla kamiennego za pomocą modelu wielokryterialnego przy ograniczeniach kosztowych, Materialy konferencji Górnictwo Zrównoważonego Rozwoju, 2011. (in Polish).

[14] R. L. Keeney, H. Raiffa, Decision with Multiple Objectives - Preferences and Value Tradeoffs, Wiley, New York, 1976.

[15] D. M. Kilgour, K. W. Hipel, N. M. Fraser, Solution concept in non-cooperative games, Large Scale Systems, (6) (1984), pp. 49-71.

[16] E. Kofler, O zagadnieniu optymalizacji wielocelowej, Przegląd statystyczny, (1) (1967). (in Polish).

[17] K. Madani, J. R. Lund, A Monte-Carlo game theoretic approach for Multi-Criteria Decision Making under uncertainty, Advances in Water Resources, (34) (2011) pp. 607-616.

[18] B. Matarazzo, Preference global frequencies in multicriterion analysis (PRAGMA), European Journal of Operational Research, (36) 1 (1988), pp, 36-49.

[19] D. W. Miller, M. K. Starr, Praktyka i Teoria Decyzji, PWN, Warszawa, 1971. (in Polish)

[20] J. F. Nash, Non-cooperative games, Annals of Mathematics, (54) 2 (1951), pp. 286-295.

[21] W. Ogryczak, Wielokryterialna Optymalizacja Liniowa $i$ Dyskretna, Wydawnictwa Uniwersytetu Warszawskiego, Warszawa, 1997. (in Polish).

[22] S. Prusek, S. Stałęga, D. Stochel, Metody i środki przeznaczone do uszczelniania i wzmacniania górotworu oraz obudowy wyrobisk, Prace Naukowe Gtównego Instytutu Górnictwa, Katowice, (863) (2005).

[23] M. Roubens, Preference relations on actions and criteria in multicriteria decision making, European Journal of Operational Research, (10) (1982), pp. 51-55.
[24] B. Roy, Méthodologie Multicritére d'aide a la Décision, Economica, Paris, 1985.

[25] T. L. Saaty, The Analytic Hierarchy Process, McGraw-Hill, NewYork, 1980.

[26] Ph. Vincke, Multicriteria Decision-Aid, John Wiley \& Sons, New York, 1992.

[27] J. von Neumann, O. Morgenstern, Theory of Games and Economic Behavior, Princeton University Press, Princeton, 1947.

[28] M. Wolny, Wspomaganie decyzji kierowniczych $w$ przedsiębiorstwie przemystowym, Wydawnictwo Politechniki Śląskiej, Gliwice, 2007. (in Polish)

[29] M. Wolny, Wielokryterialny dyskretny problem decyzyjny jako gra celów, Zeszyty Naukowe Politechniki Ślaskiej, Organizacja i Zarządzanie, Gliwice, (2) (2000). (in Polish).

[30] M. Wolny, Decision making problem with two incomparable criteria - game theory solution in: T. Trzaskalik (Ed.), Multiple Criteria Decision Making '07, AE Katowice, 2008.

[31] F. C. Zagare, Limited-move equilibria in $2 \times 2$ games, Theory and Decision, (16) (1984), pp. 1-19.

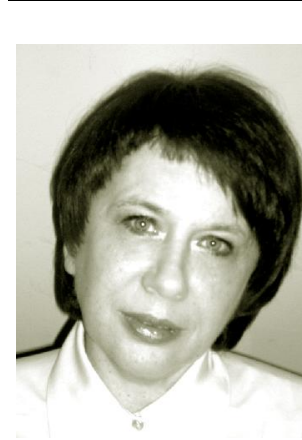

Katarzyna Jakowska-Suwalska, $\mathrm{PhD}$ in Mathematic, assistant professor at the Silesian University of Technology, scientific interests include the operational research application in management science and economics, especially, multi-criterial analysis, multi-attribute decision making problems.

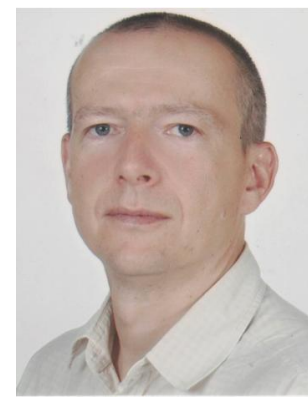

Maciej Wolny, PhD in Management Science, assistant professor at the Silesian University of Technology, scientific interests include the operational research application in management science and economics, especially, multicriterial analysis, multi-attribute decision making problems and their relationships with game theory. 